\title{
COMPARISON BETWEEN COLOR STABILITY AND POST BLEACHING HYPERSENSITIVITY OF DIFFERENT BLEACHING PROTOCOLS - RANDOMIZED SINGLE-BLINDED CONTROLLED CLINICAL TRIAL
}

\author{
Hadeel Essam Alghonaimy * , Ahmed Mohamed Hoseny Fayed **, \\ Inas Mohsen Elzayat ${ }^{* * *}$ and Adel Ezzat Khairy ${ }^{* * * *}$
}

\begin{abstract}
Objective: The aim of the study was to investigate color change, color stability and post bleaching hypersensitivity after performing 3 bleaching protocols, (LASER-activated, lightactivated and chemically-activated) at different time intervals.

Methods: Patients were randomly assigned into three treatment groups $(n=13)$. Group A received laser bleaching (J.W. Power Bleaching NEXT, $35 \%$ hydrogen peroxide), group B received light-activated bleaching (Philips ZOOM, 25\% hydrogen peroxide), and group C received chemical activated bleaching Dash Philips, 30\% hydrogen peroxide). Each group received the treatment according to the manufacturer's recommendations, followed by the desensitizing agent of each kit. Outcome assessment was performed for teeth shade and post bleaching hypersensitivity preoperatively, immediate, three months, and six months post-operatively using a spectrophotometer (Vita Easyshade, Vivadent, Germany).
\end{abstract}

Results: The study showed that there was no significant difference in color change between the three tested groups. LASER-activated bleaching protocol showed no significant difference in median $\Delta \mathrm{E}$ throughout the study. Light activated bleaching showed decrease in median $\Delta \mathrm{E}$ three to six months while in chemical-activated bleaching from zero to three months. Post-bleaching hypersensitivity, results showed no significant difference between the three tested groups as all patient experienced pain.

Conclusion: All three bleaching methods can be used upon individual's preference. LASERactivated bleaching group can be satisfactory for patients seeking good results with reduced chair time with color stability over time. Patinets of the three tested groups experienced post-bleaching hypersensitivity.

KEYWORDS: Bleaching, Post bleaching hypersensitivity, Laser, Color stability

* B.D.S Faculty of Oral and Dental Medicine, Misr International University

** Lecturer of Operative Dentistry, Faculty of Oral and Dental Medicine Misr International University

*** Assistant Professor of Operative Dentistry, Faculty of Oral and Dental Medicine Misr International University

**** Professor of Conservative Dentistry Faculty of Dentistry Cairo University 


\section{INTRODUCTION}

The paradigm shift in the aesthetic industry evolved based on the increased awareness of the patients about the minimal invasive aesthetic procedures. ${ }^{(1)}$ Bleaching is considered the most popular non-invasive cosmetic treatment done to lighten tooth shade beyond its natural color.

Bleaching is a chemical process characterized by oxidative decomposition of bleaching agents to remove external stains from the tooth surface to reach lighter tooth color. ${ }^{(3)}$ The teeth bleaching market is divided into two main groups: inoffice bleaching and at-home bleaching. In-office bleaching offers the patient less exposure time to the bleaching agent, more acceptable results, and professional control over the treatment process to ensure its effectiveness. High concentration hydrogen peroxide (25\% to $40 \%$ ) and carbamide peroxide (35\% to $38 \%$ ) are usually the agents used in in-office bleaching. ${ }^{(4)}$ They are activated either by chemical means, or external energy sources such as blue colored halogen curing lamps, advanced LED light, or light amplification by stimulated emission of radiation "laser". ${ }^{(5)}$

Chemical activated bleaching is one of the most common methods used to increase the efficiency of the bleaching process. Bleaching agents are unstable molecules that undergo dissociation once applied on the tooth surface. ${ }^{(6)}$ Chemical bleaching involves incorporating a catalyst and salts of transition metals to bleaching agents before use, in order to increase the rate of its dissociation and the formation of free radicals. ${ }^{(7)}$

It was proposed that the use of high-intensity light in bleaching acts as an accelerator for bleaching agents by increasing its temperature, thus improving the effectiveness of the treatment. ${ }^{(8)}$

Lasers were introduced to accelerate bleaching efficiency by enhancing hydrogen peroxide's oxidization effect, thus reducing patient chair time and increasing acceptance. ${ }^{(10)}$ When a laser beam strikes the tooth surface during bleaching, a portion of it will be absorbed in the particles embedded in the bleaching gel and converted to thermal energy, thus increasing the bleaching procedure's effectiveness. These particles are added to the gel to enhance laser absorption. ${ }^{(9)}$

One of the concerns of bleaching is persistence of color change for an optimum period of time. Additional adverse effects on enamel include porosities, change in microhardness, and surface roughness of enamel. ${ }^{(12)}$ The presence of microscopic enamel porosities was found to be one reason that can cause color change. ${ }^{(13)}$ The change in surface topography of an alteration in calcium phosphate ratio of tooth structure will cause surface roughness and irregularities that will affect the color stability of bleached teeth. The rough surface will be more susceptible to retain stains, and color rebound will occur. $^{(14-16)}$

Another concern is the post bleaching hypersensitivity which is the most prevalent drawback of in-office bleaching technique. ${ }^{(17)}$ Although being the most prevalent drawback, the etiology of post bleaching hypersensitivity is not yet fully understood. ${ }^{(71)}$ Many theories attempted to explain the etiology of post bleaching hypersensitivity. All the stated theories claim that hydrogen peroxide infiltrates the dental structure through surface porosities caused due to the bleaching gel. Other studies said the dehydration from the oxidative process and isolation methods are the reason for this pain provocation. ${ }^{(18)}$ There is a great controversy when it comes to state which mode of activation has the best clinical results in terms of color stability after aging. Therefore, this research was designed to assess the effect of three different in-office bleaching on color stability and post bleaching hypersensitivity. The null hypothesis of the current study stated that no difference between LASER activated bleaching, 
light activated bleaching, and chemical activated bleaching on color stability and post-bleaching hypersensitivity over a certain period of time.

\section{MATERIALS AND METHODS}

\section{Study Design}

A total of thirty-nine patients participated in this study. Patients were evaluated and selected according to inclusion and exclusion criteria after the approval of the ethical committee, with code" MIU- IRB-1617-035. (Table 1)

TABLE (1): Inclusion and exclusion criteria

\begin{tabular}{|c|c|}
\hline Inclusion criteria & Exclusion criteria \\
\hline $\begin{array}{l}\text { - Patients between } 18 \text { and } \\
45 \text { years old }{ }^{(8,59)}\end{array}$ & $\begin{array}{l}\text { - Existing anterior crowns } \\
\text { or any restorations on } \\
\text { anterior teeth that will } \\
\text { interfere with the bleach- } \\
\text { ing process. }\end{array}$ \\
\hline $\begin{array}{l}\text { - Presence of six sound } \\
\text { maxillary anterior teeth. }\end{array}$ & $\begin{array}{l}\text { - Smoker or alcoholic pa- } \\
\text { tient. }\end{array}$ \\
\hline $\begin{array}{l}\text { - Patient having brown or } \\
\text { yellowish stains. }\end{array}$ & $\begin{array}{l}\text { - Patients suffering from } \\
\text { active periodontal dis- } \\
\text { eases and exposed roots. }\end{array}$ \\
\hline $\begin{array}{l}\text { - Good oral health main- } \\
\text { tained by routine brush- } \\
\text { ing. }\end{array}$ & $\begin{array}{l}\text { - Severe intrinsic tooth } \\
\text { discoloration such as } \\
\text { tetracycline staining or } \\
\text { dental fluorosis. }\end{array}$ \\
\hline $\begin{array}{l}\text { - Generalized tooth stain- } \\
\text { ing ranging from A2 or } \\
\text { darker according to the } \\
\text { value-oriented shade } \\
\text { guide (Vita easy shade). }\end{array}$ & $\begin{array}{l}\text { - Patient with history of } \\
\text { teeth hypersensitivity. }\end{array}$ \\
\hline \multirow[t]{2}{*}{$\begin{array}{l}\text { - Patient is willing to sign } \\
\text { a consent form and can } \\
\text { attend all recall visits. }\end{array}$} & $\begin{array}{l}\text { - Patient who undergone } \\
\text { previous whitening pro- } \\
\text { cedure. }\end{array}$ \\
\hline & $\begin{array}{l}\text { - Pregnant and lactating } \\
\text { women. }^{(8)}\end{array}$ \\
\hline
\end{tabular}

All participants signed a consent form adapted to the local language before starting the study. They agreed upon joining the experiment to be present at and three months and six-month recall visits. Patients were examined thoroughly at Misr International University out-patient clinic. Medical and dental history were recorded in the patient's file that is available at the facility.

The selected patients were divided equally into three groups ( $n=13)$ according to treatment: 1 . Laser-activated bleaching system using 35\% hydrogen peroxide (NEXTHeyDent $\mathrm{GmbH}$, Kaufering, Germany) with the corresponding Epic $\mathrm{X}$, BIOLASE diode laser machine (wavelength 940 nanometer), 2. Light-activated bleaching using $25 \%$ hydrogen peroxide (ZOOM! Chairside tooth whitening system, Discus Dental, Inc., Culver City, CA, USA), and 3. Chemical activated bleaching using 30\% hydrogen peroxide (Philips Dash, Discus Dental).

Sample size determination was based upon the results of Liang $S$ et al. (2013). Using alpha level of $0.05(5 \%)$ and $\beta$ level of 0.20 (20\%), i.e., power $=80 \%$; the estimated minimum required sample size (n) was 10 participants per group, giving a total of 30 patients. Over-sampling was performed to compensate for the $25 \%$ drop-out rate so the required sample size is a minimum of 13 participants per group giving 39 participants. ${ }^{(23)}$

Allocation concealment was achieved successfully using a sealed coded opaque envelope containing the subject's treatment protocol. The envelope was opened the day of bleaching. Outcome assessment done by the co-investigator was performed for teeth shade preoperatively.

\section{Material}

Material's composition and manufacturer's company name are presented in the Table (2). 
TABLE (2): Materials used in the study, composition and manufacturer's company name

\begin{tabular}{|l|l|l|l|}
\hline Character & Materials & Composition & Manufacturer \\
\hline $\begin{array}{l}\text { In-office Laser } \\
\text { activated bleaching }\end{array}$ & $\begin{array}{l}\text { JW power bleaching } \\
\text { NEXT }\end{array}$ & $\begin{array}{l}\text { Two component bleaching gel in adouble-bar cartridge } \\
\text { with 35\% hydrogen peroxide }\end{array}$ & $\begin{array}{l}\text { Heydent } \\
\text { Kaufering, Germany }\end{array}$ \\
\hline $\begin{array}{l}\text { In-office photo } \\
\text { catalyzed bleaching } \\
\text { agent. }\end{array}$ & Philips ZOOM & $\begin{array}{l}\text { 25\% hydrogen peroxide, water, poloxomer, Glycerin, } \\
\text { Glycol, Potassium nitrate, potassium hydroxide, Mentha } \\
\text { pipe Rita, Eugenol, and Ferrous gluconate. }\end{array}$ & $\begin{array}{l}\text { Philips, Discus Dental, } \\
\text { U.S.A }\end{array}$ \\
\hline $\begin{array}{l}\text { In-office chemo } \\
\text { catalyzed bleaching }\end{array}$ & Philips Dash & $\begin{array}{l}30 \% \text { hydrogen peroxide, water, glycerin, hydroxyethyl } \\
\text { acrylate, sodium acryloyldimethyltaurate copolymer, } \\
\text { etidronic acid, potassium stannate, ammonium } \\
\text { hydroxide. }\end{array}$ & Discus Dental, U.S.A \\
\hline Desensitizing agent. & Relief ACP & $\begin{array}{l}\text { Potassium Nitrate, Sodium Fluoride, water, Poloxamer, } \\
338, \text { Natural Mentha pipe Rita, Calcium Nitrate, Sodium } \\
\text { Phosphate, Sodium saccharin. }\end{array}$ & $\begin{array}{l}\text { Philips, Discus Dental, } \\
\text { U.S.A }\end{array}$ \\
\hline
\end{tabular}

\section{Patient preparation}

\section{Oral hygiene Measures}

Scaling was done using an ultrasonic scaler (various 350, NSK, Japan) followed by polishing using a low-speed brush and a non-fluoridated polishing paste (Cleanic ${ }^{\mathrm{tm}}$ polishing paste, Kerr, Switzerland).

\section{Impression-taking}

A primary alginate impression (Tropicalgin, Zhermak, Italy) of the maxillary arch was taken to create two vacuum sheet trays. The impression was poured, and a cast was created. Vacuum sheet trays were fabricated afterwards using $2 \mathrm{~mm}$ thick vinyl soft sheets (Sof-Tray ${ }^{\mathrm{TM}}$, Ultra Dent, U.S.A.). The first tray was created without spacer, a $6 \mathrm{~mm}$ diameter hole was drilled by round diamond stone in the middle of the upper right central incisor to act as a guidance for the tip of spectrophotometer during color recordings throughout the follow up visits. The second tray was for delivering the desensitizing agent associated with each kit.

\section{Shade recordings}

Before shade recording, VITA Classic Easy Shade Spectophotmeter (Vita Zahnfabrik H. Rauter GmbH \& Co.KG, Bad Sackingen.Germany) was calibrated according to manufacturer's instructions. To calibrate the device, the base unit was connected to a power source, the tip was placed on the calibration block and calibration switch was pressed. A 3-beeps were heard when the calibration has been done successfully. This process is done prior to each shade recording.

Vita Classic Easy Shade Spectrophotometer was used before treatment to record the baseline color of the upper six anterior teeth. Patient was instructed to wear the vacuum sheet special tray and the shade is determined through the drilled hole. ${ }^{(88)}$ The tooth measurement icon was selected from the menu that appeared on the device screen. The tip of the device was placed properly in the drilled hole on the middle-middle of right maxillary central incisor and perpendicular to the tooth surface. The measurement switch was pressed to start recording. Beep indicated termination of the process. The screen then showed the result in both VITAPAN classical shade guide and 3D master 
shade guide. A detailed description of the color was available on the screen.

\section{Bleaching protocols}

\section{Laser activated bleaching protocol}

The diode LASER machine (Epic X, BIOLASE Inc., U.S.A.) wavelength 940 nanometer is plugged to a power source. The device was turned on and set on standby mode before the placement of the whitening tip. Whitening tip was placed to the handpiece. The footswitch associated with the device was connected by wireless means. The blue L.E.D. blinking light gives the indication that footswitch is successfully connected. Epic protective eyewear was given to the patient and the operator to avoid eye damage from LASER beam. Vaseline was applied on patient's lips and cheek retractor was placed to retract lips and cheeks from teeth and protect them from getting in contact with the bleaching gel. Gingiva was properly dried and Gingival protector liquid dam is applied on all the exposed gingiva to avoid leakage of the gel. The gingival protector was set by a light curing device (Dental Woodpecker L.E.D. curing light, Star Dent, shade.China) for 10 second in back-and-forth movement. Cotton rolls and saliva ejector were applied in the vestibules to ensure proper isolation.

Bleaching gel (J.W. Power Bleaching NEXT, Heydent, Germany) cap was removed, and mixing tip was applied on the gel syringe. The gel was then applied on maxillary six anterior teeth in an even non streaky thin layer of $2 \mathrm{~mm}$ according to the manufacturer's instructions. LASER device power setting was adjusted to power $7 \mathrm{~W}$ and operation mode was set to continuous wave mode. Bleaching procedure was initiated by the placement of the bleaching tip on the teeth, and the LASER beam was fired. The footswitch was pressed for thirty seconds. The upper arch was divided into two right and left quadrants, each quadrant received 30 seconds of LASER beam. The delivered energy per quadrant was 210 joules. It was calculated using the equation energy $(\mathrm{J})=$ power $(\mathrm{W}) \times$ time $(\mathrm{s})$. The process was repeated for another 30 seconds for the same gel application. Afterwards, the gel was removed by a suction tip and thoroughly flushed then teeth were dried to be prepared for the second application of the gel. The remaining gel was applied to the teeth and two more LASER doses were received. Each laser dose lasted for 30 seconds. Gel was removed by suction tip and teeth were rinsed properly to regain tooth hydration then liquid dam was removed. After that the patient was asked to wear the drilled special tray for after treatment recording of the shade. Patient was asked to wear the tray for thirty minutes as per manufacturer's instructions. The patient was given a tray to deliver the "relief A.C.P." desensitizing agent. Afterwards, patient was given the post-operative instructions to follow. Finally, post bleaching hypersensitivity assessment took place. An air spray was subjected to the bleached teeth and patients were asked to assess pain by Visual Analog Scale from 0-10.

\section{Light-activated bleaching protocol}

The bleaching was applied on the teeth and mixed by the brush to activate the gel. Gel was applied evenly on the teeth. The light guide was attached to the zoom light accelerator device. According to manufacturer's instructions, patients received three sessions of 15 minutes each. After the termination of treatment, liquidam, cotton and gauze were removed, shade recording took place through the drilled hole of the special tray and then the patient received the "relief A.C.P." desensitizing agent in the vacuum sheet for 30 minutes. Afterwards, air spray was used on the bleached teeth to assess post bleaching hypersensitivity and patient was asked to assess the pain using Visual Analog Scale from $0-10$.

\section{Chemical activated bleaching protocol}

A whitening accelerator swab was applied to the teeth as per manufacturer's instructions to chemically activate the bleaching gel. The bleaching 
gel was applied in an even layer over the teeth. The patients in this group received three sessions that lasted for 15 minutes each. The bleaching gel was removed using suction tip and rinsed by water and air spray after every session. Upon finishing the treatment, isolation means were removed, and shade was recorded. Patient received the relief A.C.P. desensitizing agent in the customized vacuum sheet tray for 30 minutes. Post bleaching hypersensitivity assessment took place at this stage using air spray. Patient was asked to assess the pain using Visual Analog Scale (V.A.S) from 0-10. 0 indicated no pain while 10 indicates severe pain.

\section{Color assessment}

Each patient had color recording at baseline, immediately after treatment, 3 and 6 months after termination of treatment. Shade evaluation was done by Vita EasyShade 4.0 spectrophotometer. Before shade recording, Vita EasyShade was calibrated according to manufacturer's instructions. Vita EasyShade spectrophotometer was used before treatment to record the baseline color of teeth. VITA EasyShade uses the parameters of the digital spectrophotometer having the following values of color coordinates CIE: L*, $\left(a^{*}\right)$, and $\left(b^{*}\right)$, in which $L^{*}$ represents the value from 0 to 100 and $a^{*}$ and $b^{*}$ represent the shade, where $a^{*}$ denotes the measurement along the red-green axis and $b^{*}$ represents the yellow-blue axis. ${ }^{(67)}$ The shade comparison before and after treatment will be given by the differences between the two shades $(\Delta \mathrm{E})$, which is calculated using the formula:

$$
\left(\Delta \mathrm{E}=\sqrt{\left(\Delta \mathrm{L}^{*}\right) 2+\left(\Delta \mathrm{b}^{*}\right) 2+\left(\Delta \mathrm{a}^{*}\right) 2}\right)
$$

Patient was instructed to wear the vacuum sheet special tray and the shade was determined through the drilled hole for accurate reading. ${ }^{(58)}$ An outcome assessor was chosen to record results, was blinded to which bleaching protocol was performed on the patient.

\section{Hypersensitivity assessment}

Hypersensitivity was the second outcome in this study. It was evaluated by V.A.S Visual analogue scale. Patients were asked to evaluate the pain from 0-10; 0 indicated no pain, while 10 indicated severe pain. Teeth sensitivity was assessed immediately after treatment, after 3 and 6 months.

All patients were advised to follow few instructions to ensure the success of the treatment plan. Patients were instructed to avoid colored food and beverages for at least 48 hours. They were also asked to use the prescribed non-fluoridated nonwhitening toothpastes. Proper hygiene measures were advised, such as brushing teeth twice a-day and flossing after meals.

Lower arch results were not included in this study, but patients did undergo bleaching for both upper and lower teeth for ethical reasons.

\section{Statistical Analysis}

Numerical data were explored for normality by checking the distribution of data and using tests of normality (Kolmogorov-Smirnov and Shapiro-Wilk tests). Age data showed parametric distribution, while pain scores as well as color parameters showed non-parametric distribution. Numerical data were presented as mean, standard deviation (SD), median and range values. For parametric data; one-way ANOVA test was used to compare between mean age values in the three groups. For non-parametric data; Kruskal-Wallis test was used to compare between the three groups. Friedman's test was used to study the changes within each group. Dunn's test was used for pair-wise comparisons. Qualitative data were presented as frequencies and percentages. Chi-square test was used for comparisons between the three groups. The significance level was set at $\mathrm{P} \leq 0.05$. Statistical analysis was performed with IBM SPSS Statistics for Windows, Version 23.0. Armonk, NY: IBM Corp. 


\section{RESULTS}

\section{Color change $(\Delta \mathrm{E})$}

\section{Comparison between groups}

Comparison between the three groups showed that there was no statistically significant difference between median $\Delta \mathrm{E}$ in the three groups immediately post-operative, after 3 as well as 6 months ( $P$-value $=0.170$, Effect size $=0.043),(P$-value $=0.227$, Effect size $=0.027)$ and $(P$-value $=0.189$, Effect size $=0.037)$, respectively. Table (3)

\section{Changes Within Each Group}

Table 4 represents descriptive statistics and results of Friedman's test for comparison between $\Delta \mathrm{E}$ within each group.

As regards LASER group; there was no statistically significant change in median $\Delta \mathrm{E}$ through all follow up times $(P$-value $=0.368$, Effect size $=0.077)$.

While for ZOOM group; there was a statistically significant change in median $\triangle \mathrm{E}$ by time $(P$-value $=$ 0.040 , Effect size $=0.247$ ). Pair-wise comparisons between time periods revealed that there was no statistically significant change in $\Delta \mathrm{E}$ from immediately after twenty-four hours of treatment to 3 months' period. From 3 to 6 months; there was a statistically significant decrease in median $\Delta \mathrm{E}$.

As regards Dash group; there was a statistically significant change in median $\Delta \mathrm{E}$ by time $(P$-value $=$ 0.009 , Effect size $=0.359$ ). Pair-wise comparisons between time periods revealed that there was a statistically significant decrease in median $\Delta \mathrm{E}$ from immediately after twenty-four hours of treatment to 3 months' period. From 3 to 6 months; there was no statistically significant change in median $\Delta \mathrm{E}$.

\section{Assessment of pain}

Comparison between the three groups showed that there was no statistically significant difference between median pain scores. Most of the patients experienced mild pain except two participants in the laser activated group had no pain post operatively and one participant experienced severe pain in the light-activated bleaching group. $(P$-value $=0.059$, Effect size $=0.102)$. Table (5)

TABLE (3): Descriptive statistics and results of Kruskal-Wallis test for comparison between $\Delta \mathrm{E}$ in the three groups

\begin{tabular}{|c|c|c|c|c|c|c|}
\hline & $\Delta \mathrm{E}$ & $\begin{array}{l}\text { Laser } \\
(\mathrm{n}=13)\end{array}$ & $\begin{array}{l}\text { Zoom } \\
(\mathrm{n}=13)\end{array}$ & $\begin{array}{l}\text { Dash } \\
(\mathrm{n}=13)\end{array}$ & $\begin{array}{l}P \text {-value (between } \\
\text { groups) }\end{array}$ & $\begin{array}{l}\text { Effect size (Eta } \\
\quad \text { Squared) }\end{array}$ \\
\hline \multirow{2}{*}{ Immediate } & Median (Range) & $12.9(3.9-16.2)$ & $10(1.7-16.5)$ & $7.2(5.1-16.5)$ & \multirow{2}{*}{0.170} & \multirow{2}{*}{0.043} \\
\hline & Mean (SD) & $12.1(3.8)$ & $9.8(4.6)$ & $9.4(3.7)$ & & \\
\hline \multirow{2}{*}{3 months } & Median (Range) & $12.9(3.9-16.2)$ & $10(1.7-16.3)$ & $6.9(5.1-17.1)$ & \multirow{2}{*}{0.227} & \multirow{2}{*}{0.027} \\
\hline & Mean (SD) & $11.8(3.9)$ & $9.7(4.4)$ & $9.3(4.1)$ & & \\
\hline \multirow{2}{*}{6 months } & Median (Range) & $11.2(3.9-16.2)$ & $10(1.4-14.3)$ & $6.9(5.1-14.9)$ & \multirow{2}{*}{0.189} & \multirow{2}{*}{0.037} \\
\hline & Mean (SD) & $11.4(4.1)$ & $8.9(4.7)$ & $8.7(3.4)$ & & \\
\hline
\end{tabular}

*: Significant at $P \leq 0.05$ 
TABLE (4): Descriptive statistics and results of Friedman's test for comparison between $\Delta \mathrm{E}$ within each group

\begin{tabular}{|c|c|c|c|c|c|c|}
\hline & $\Delta \mathrm{E}$ & $\begin{array}{l}\text { LASER- } \\
\text { activated } \\
(\mathrm{n}=13)\end{array}$ & $\begin{array}{l}\text { Light- } \\
\text { activated } \\
(\mathrm{n}=13)\end{array}$ & $\begin{array}{c}\text { Chemical-activated } \\
\qquad(\mathrm{n}=13)\end{array}$ & $\begin{array}{c}P \text {-value } \\
\text { between } \\
\text { groups }\end{array}$ & $\begin{array}{c}\text { Effect size (Eta } \\
\text { Squared) }\end{array}$ \\
\hline \multirow[t]{2}{*}{$\begin{array}{l}\text { Immediately after } \\
\text { twenty-four hours }\end{array}$} & $\begin{array}{l}\text { Median } \\
\text { (Range) }\end{array}$ & $\begin{array}{c}12.9 \\
(3.9-16.2)\end{array}$ & $\begin{array}{c}10 \\
(1.7-16.5)^{\mathrm{A}}\end{array}$ & $\begin{array}{c}7.2 \\
(5.1-16.5)^{\mathrm{A}}\end{array}$ & \multirow[t]{2}{*}{0.170} & \multirow[t]{2}{*}{0.043} \\
\hline & Mean (SD) & $12.1(3.8)$ & $9.8(4.6)$ & $9.4(3.7)$ & & \\
\hline \multirow[t]{2}{*}{3 months } & $\begin{array}{l}\text { Median } \\
\text { (Range) }\end{array}$ & $\begin{array}{c}12.9 \\
(3.9-16.2)\end{array}$ & $\begin{array}{c}10 \\
(1.7-16.3)^{\mathrm{A}}\end{array}$ & $\begin{array}{c}6.9 \\
(5.1-17.1)^{\mathrm{B}}\end{array}$ & \multirow[t]{2}{*}{0.227} & \multirow[t]{2}{*}{0.027} \\
\hline & Mean (SD) & $11.8(3.9)$ & $9.7(4.4)$ & $9.3(4.1)$ & & \\
\hline \multirow[t]{2}{*}{6 months } & $\begin{array}{l}\text { Median } \\
\text { (Range) }\end{array}$ & $\begin{array}{c}11.2 \\
(3.9-16.2)\end{array}$ & $\begin{array}{c}10 \\
(1.4-14.3)^{\text {в }}\end{array}$ & $\begin{array}{c}6.9 \\
(5.1-14.9)^{\text {в }}\end{array}$ & \multirow[t]{2}{*}{0.189} & \multirow[t]{2}{*}{0.037} \\
\hline & Mean (SD) & $11.4(4.1)$ & $8.9(4.7)$ & $8.7(3.4)$ & & \\
\hline \multicolumn{2}{|c|}{$P$-value (Within group) } & 0.368 & $0.040^{*}$ & $0.009 *$ & & \\
\hline \multicolumn{2}{|c|}{ Effect size $(w)$} & 0.077 & 0.247 & 0.359 & & \\
\hline
\end{tabular}

*: Significant at $P \leq 0.05$, Different superscripts in the same column are statistically significantly different

TABLE (5): Descriptive statistics and results of Kruskal-Wallis test for comparison between pain scores in the three groups

\begin{tabular}{|c|c|c|c|c|c|}
\hline Pain score & $\begin{array}{c}\text { Laser } \\
(\mathrm{n}=13)\end{array}$ & $\begin{array}{c}\text { Zoom } \\
(\mathrm{n}=13)\end{array}$ & $\begin{array}{c}\text { Dash } \\
(\mathrm{n}=13)\end{array}$ & P-value (between groups) & Effect size (Eta Squared) \\
\cline { 1 - 3 } Median (Range) & $4(0-7)^{\mathrm{A}}$ & $6(0-9)^{\mathrm{A}}$ & $5(3-8)^{\mathrm{A}}$ & \multirow{2}{*}{0.059} & 0.102 \\
\hline Mean (SD) & $4(1.9)$ & $5.9(2.5)$ & $5.2(1.8)$ & \\
\hline
\end{tabular}

*: Significant at $P \leq 0.05$

\section{DISCUSSION}

Bleaching is known as the decomposition of the stains entrapped in the tooth's outer layer, known as enamel, to reach a lighter shade. Stains are classified into intrinsic and extrinsic. Intrinsic discoloration usually occurs during the development phase of the tooth.

In contrast, extrinsic discoloration results from the ingestion of colored foods and beverages such as coffee, tea, red wine, or smoking ${ }^{(61)}$. Excessive fluoride intake during tooth development will initiate dental fluorosis, which is a common cause of intrinsic stains, as well as the ingestion of tetracycline. Pulpal hemorrhage and amalgam tattoo are also classified under intrinsic stains. Vital tooth bleaching is considered the optimum and the minimally invasive approach to treating the extrinsic type of discoloration. ${ }^{(62,63)}$

The current study assessed three different in-office bleaching protocols regarding color stability immediately after treatment, and at three months and six months after application. A lightactivated bleaching protocol (Philips ZOOM!) chemically activated bleaching protocol (Philips 
Dash), and laser-activated bleaching protocol (JW NEXT heydent) were compared. The bleaching gel concentrations were $25 \%, 30 \%$, and $35 \%$, respectively.

Vita easy shade was chosen, instead of manual shade selection in the current study for its accuracy, reliability, reproducibility, and eliminates the errors that might occur from the human eye ${ }^{(67,68)}$. Dozic et al. stated that Vita EasyShade is more accurate than colorimeters, such as IdentaColorII and ShadeEye. ${ }^{(68)}$

Shade evaluation was assessed before bleaching as a baseline, immediately after treatment, at three months, and at six months after treatment to evaluate color stability.

The results of the present study showed that all three groups produced a whitening effect after treatment. When comparing between the three groups, no statistically significant difference between median $\Delta \mathrm{E}$ was found after twenty-four hours of treatment, 3 and 6 months after treatment $(P$-value $=0.170$, Effect size $=0.043),(P$-value $=0.227$, Effect size $=0.027)$ and $(P$-value $=$ 0.189 , Effect size $=0.037)$, respectively. Results matched Farzaneh Ahrari et al. ${ }^{(16)}$, who compared four bleaching protocols and found no significant difference between tested groups. Petra Hahn et al. ${ }^{(27)}$ and Hazar et al ${ }^{(41)}$ results were in agreement with the current study. Bernardon et al. ${ }^{(79)}$ corroborate our findings that light and laser, as modes of the activation, did not influence the degree of brightness of teeth after bleaching. This could be explained by the oxidative reaction of the peroxide based bleaching agent. When hydrogen peroxide gel gets activated, it dissociates. Releasing hydroxyl free radicals, per-hydroxyl radicals and superoxide anion which will attack and break down the double bond of the protein chains of the stain molecule. Teeth are now absorbing more light with minimal reflection. Thus, teeth will appear lighter in color. ${ }^{(77,87)}$
Fekrazad et al. ${ }^{(75)}$ concluded that laser bleaching using diode laser resulted in significantly better whitening results, than the conventional in-office technique with Opalescence Xtra Boost ${ }^{\circledR}$. Which doesn't agree with the current study. Calatayud et al. ${ }^{(25)}$ also showed that diode laser usage combined with $35 \%$ hydrogen peroxide had better clinical efficiency than other bleaching protocols. Similarly, Young et al. ${ }^{(20)}$ and Hayward et al. ${ }^{(76)}$ found that the use of light in addition to the bleaching gel will enhance bleaching efficacy and produce lighter color than chemical bleaching protocol. The disagreement between these results and the current study might be attributed to the different concentrations of bleaching gel used, and the baseline color of the tested teeth and the exposure time to bleaching gel.(77)

To evaluate color stability, comparing the change in $\Delta \mathrm{E}$ took place within each group throughout the follow-up periods.

In the laser group, no significant change in median $\Delta \mathrm{E}$ was noted throughout the clinical trial. The results indicated that laser-activated bleaching showed color stability until the termination of the study, while the light-activated group showed color relapse between 3 to 6 months period of the clinical trial. The chemical activated group on the other hand showed color relapse between the period of 0-3 months postoperatively. These results are in agreement with Ahrari et al. ${ }^{(16)}$, who found out that the laser-activated bleaching technique showed the least color relapse when compared to other in-office and at-home bleaching protocols. Bilichodmath $\mathrm{S}$ et al. ${ }^{(39)}$ concluded that diode laser had significantly better results when compared with chemical and LED activated bleaching techniques ${ }^{(11)}$. Bacaksiz A et al. ${ }^{(78)}$ disagrees with the current study as they concluded that the result of the current clinical trial showed that LED-activated bleaching had better color stability over time.

Hypersensitivity is one of the most common side effect of the bleaching procedure. ${ }^{(80,81)}$ Sensitive teeth respond aggressively to the simplest stimuli. 
The hydrodynamic theory proposed by Brännström in 1964 suggests that hypersensitivity is perceived as pain and is generated by dentinal fluid's dynamic movement within dentinal tubules. ${ }^{83,84)}$ This results in the excitation of pulp's mechanoreceptors, when subject to a stimulus. ${ }^{\left({ }^{(3)}\right)}$ Dentinal hypersensitivity ranges from mild discomfort to severe pain, depending on an individual's pain threshold.

Post bleaching hypersensitivity occurs, although dentine and dentinal tubules do not get exposed during the bleaching procedure. Several theories have been discussed to verify the reason behind the post-treatment hypersensitivity phenomenon.

One theory described sensitivity related to hydrodynamic theory.

Hydrogen peroxide free radicals penetrate the tooth structure, resulting in a fluid movement in the dentinal tubules. This triggers nerve endings' stimulation, generating sensitivity. It was suggested that the higher in-office treatments concentrations resulted in a greater degree of dentin hypersensitivity than procedures undertaken at home. ${ }^{\left({ }^{(4)}\right.}$

A 2nd theory suggests that bleaching can cause pulpal inflammation resulting in the release of inflammatory mediators, such as prostaglandins and adenosine triphosphate. ${ }^{(85,86)}$

A 3rd theory is the TRPA1 activation theory as hypothesized by Theison. It stated that post bleaching hypersensitivity occurs as a consequence of functional properties of a chemo-sensitive ion channel called TRPA1 "transient receptor potential cation channel with ankyrin domain type 1". This ion channel is associated with pain caused by oxidants such as hydrogen peroxide. As dental pulp contains TRPA1, direct TPRA1 activation of afferent nerve fibers might be related to post bleaching hypersensitivity. ${ }^{(88)}$

Post bleaching hypersensitivity was examined in the present clinical trial by Visual Analogue Scale (VAS) ranging from 0-10. Visual Analog Scale is a subjective tool to measure pain intensity. In the present study, 0 scores represented no pain, and ten scores represented severe pain. In agreement with Alexander L. et al. ${ }^{(60)}$ and Klarić E. et al. ${ }^{(17)}$ teeth sensitivity was assessed throughout the experiment period using a validated qualitative tool (VAS). It took place immediately after treatment, two weeks post-treatment, and after three and six months.

The current study results showed no statistically significant difference between mean pain scores $(\mathrm{P}$-value $=0.059$, Effect size $=0.102)$, which means that the three bleaching protocols induced postoperative hypersensitivity. The results contradict Moosavi et al. ${ }^{(54)}$, Mohammed Abbood Al-Maliky ${ }^{(58)}$, and Ahrari F. et al. ${ }^{(16)}$ They found that the laser bleaching group had the least postoperative hypersensitive among other bleaching groups. The variance in results occurred due to a difference in the diode laser's power setting between the studies. On the other hand, Lo Giudice R. et al. ${ }^{(53)}$ results matched the current research and showed no difference in sensitivity between different bleaching protocols as all participant experienced post bleaching hypersensitivity. The author explained the increase in pain after bleaching was due to an increase of the internal temperature of the pulp chamber within a healthy range and status.

The null hypothesis of the study was rejected as the tested groups (Laser activated bleaching, Light activated bleaching, and Chemical activated bleaching) had no statistically significant difference regarding color change, but Laser activated bleaching had the best efficiency regarding color stability over time.

\section{CONCLUSION}

All three bleaching methods were effective in improving teeth color and can be used according to individual's fondness. All participants experienced degrees of postoperative hypersensitivity. 


\section{REFERENCES}

1. Martos J, Kinalski M. Combined in-office and takehome bleaching in vital teeth. J Restor Dent. 2014 Sep 1; 2(3):149-53.

2. Kiyak HA. Does orthodontic treatment affect patients' quality of life? J Dent Educ. 2008 Aug;72(8):886-94.

3. Zantner C, Beheim-Schwarzbach N, Neumann K, Kielbassa AM. Surface microhardness of enamel after different home bleaching procedures. Dent Mater. 2007 Feb;23(2):243-50.

4. Farah JW, Powers JM. In office and home bleaching. Dent Advis. 1996;13:1-8.

5. White DJ, Kozak KM, Zoladz JR, Duschner H, Götz H. Peroxide interactions with hard tissues: effects on surface hardness and surface/subsurface ultrastructural properties. Compend Contin Educ Dent. 2002 Jan;23(1A):42-8.

6. Hardman PK, Moore DL, Petteway GH. Stability of hydrogen peroxide as a bleaching agent. Gen Dent. 1985; 33(2):121-2.

7. Torres CRG, Wiegand A, Sener B, Attin T. Influence of chemical activation of a $35 \%$ hydrogen peroxide bleaching gel on its penetration and efficacy-In vitro study. J Dent. 2010;38(10):838-46.

8. Dental Association A. Tooth Whitening/Bleaching: Treatment Considerations for Dentists and Their Patients ADA Council on Scientific Affairs. 2009.

9. Freedman GA, Greenwall L. Bleaching techniques in restorative dentistry : an illustrated guide. London: Martin Dunitz; 2001, ch.7:132-158.

10. Lima DANL, Aguiar FHB, Liporoni PCS, Munin E, Ambrosano GMB, Lovadino JR. In vitro evaluation of the effectiveness of bleaching agents activated by different light sources. J Prosthodont Off J Am Coll Prosthodont. 2009 Apr;18(3):249-54.

11. Wetter NU, Barroso MCS, Pelino JEP. Dental bleaching efficacy with diode laser and LED irradiation: An in vitro study. Lasers Surg Med. 2004;35(4):254-8.

12. Abdelfattah MM. Different Types of Laser use in Teeth Bleaching. J Med Med Sci. 2014;5(10):230-7.

13. Sulieman M, MacDonald E, Rees JS, Addy M. Comparison of three in-office bleaching systems based on 35\% hydrogen peroxide with different light activators. Am J Dent. 2005 Jun;18(3):194-7.
14. Goldberg M, Grootveld M, Lynch E. Undesirable and adverse effects of tooth-whitening products: a review. Clin Oral Investig. $2010 \mathrm{Feb}$;14(1):1-10.

15. Côrtes G, Pini NP, Lima DANL, Liporoni PCS, Munin E, Ambrosano GMB, et al. Influence of coffee and red wine on tooth color during and after bleaching. Acta Odontol Scand. 2013 Nov;71(6):1475-80.

16. Ahrari F, Akbari M, Mohammadipour HS, Fallahrastegar A, Sekandari S. The efficacy and complications of several bleaching techniques in patients after fixed orthodontic therapy. A randomized clinical trial. Swiss Dent J. 2020;130(6):493-501.

17. Klarić E, Profeta I, Matošević D, Tarle Z. Postoperative sensitivity after two in-office bleaching methods. Acta Stomatol Croat. 2011;45(2):100-9.

18. Palé M, Mayoral JR, Llopis J, Vallès M, Basilio J, Roig M. Evaluation of the effectiveness of an in-office bleaching system and the effect of potassium nitrate as a desensitizing agent. Odontology. 2014;102(2):203-10.

19. Matis BA, Cochran MA, Franco M, Al-Ammar W, Eckert GJ, Stropes M. Eight in-office tooth whitening systems evaluated in vivo: a pilot study. Oper Dent. 2007; 32(4):322-7.

20. Young N, Fairley P, Mohan V, Jumeaux C. A study of hydrogen peroxide chemistry and photochemistry in tea stain solution with relevance to clinical tooth whitening. J Dent. $2012 ; 40$ (Suppl 2):e11-6.

21. Kwon SR, Oyoyo U, Li Y. Effect of light activation on tooth whitening efficacy and hydrogen peroxide penetration: An in vitro study. J Dent. 2013;41:e39-45.

22. Vano M, Derchi G, Barone A, Genovesi A, Covani U. Tooth bleaching with hydrogen peroxide and nano-hydroxyapatite: a 9-month follow-up randomized clinical trial. Int J Dent Hyg. 2015;13(4):301-7.

23. Liang S, Sa Y, Jiang T, Ma X, Xing W, Wang Z, et al. In vitro evaluation of halogen light-activated vs chemically activated in-office bleaching systems. Acta Odontol Scand. 2013;71(5):1149-55.

24. Kugel G, Ferreira S, Sharma S, Barker ML, Gerlach RW. Clinical trial assessing light enhancement of in-office tooth whitening. J Esthet Restor Dent. 2009;21(5):336-47.

25. Calatayud JO, Calatayud CO, Zaccagnini AO, Box MJ. Clinical efficacy of a bleaching system based on hydrogen peroxide with or without light activation. Eur J Esthet Dent. 2010;5:216-24. 
26. Roche Hayward YO, Grobler SR. A clinical study of the effectiveness of a light emitting diode system on tooth bleaching. Open Dent J. 2012;6:143-7.

27. Hahn P, Schondelmaier N, Wolkewitz M, Altenburger MJ, Polydorou O. Efficacy of tooth bleaching with and without light activation and its effect on the pulp temperature: An in vitro study. Odontology. 2013;101(1):67-74.

28. De Oliveira Duque CC, Soares DG, Basso FG, Hebling J, de Souza Costa CA. Bleaching effectiveness, hydrogen peroxide diffusion, and cytotoxicity of a chemically activated bleaching gel. Clin Oral Investig. 2014;18(6):1631-7.

29. Zhao K, Zong L, Zhang Q, Att W. Clinical comparison between two bleaching techniques: A 180-day follow-up study. Quintessence Int. 2013;44(8):601-607

30. Al-Harbi A, Ardu S, Bortolotto T, Krejci I. Effect of extended application time on the efficacy of an in-office hydrogen peroxide bleaching agent: an in vitro study. Eur J Esthet Dent. 2013;8(2):226-36.

31. Machado LS, de Oliveira FG, Rocha EP, dos Santos PH, Briso AL, Sundefeld ML, et al. Clinical trial evaluating color change and tooth sensitivity throughout and following in-office bleaching. Int J Periodontics Restorative Dent. 2013;33(2):209-15.

32. Caneppele TM, Borges AB, Torres CR. Effects of dental bleaching on the color, translucency and fluorescence properties of enamel and dentin. Eur J Esthet Dent. 2013;8.

33. Baroudi K, Hassan N. The effect of light-activation sources on tooth bleaching. Niger Med J. 2014;55(5):363.

34. Sabbagh J, El Masri L, El Hajj M, Khafaja S, Nahas P. One-year Clinical Evaluation of a New Bleaching Product Used with and without Light. J Int Oral Heal. 2016; 8(2):153-157.

35. Fonseca AML da, Tuñas IC, Vidal F, Pires FR, Gonçalves LS. Dental bleaching with and without LED/Laser association: a split-mouth controlled study. Revistas. 2016 Dec 27;73(4):267.

36. Bhutani N, Venigalla B, Patil J, Singh T, Jyotsna S, Jain A. Evaluation of bleaching efficacy of $37.5 \%$ hydrogen peroxide on human teeth using different modes of activations: An in vitro study. J Conserv Dent. 2016 May 1;19(3):259.

37. Vildosola P, Vera F, Ramirez J, Rencoret J, Pretel H, Oliveira $\mathrm{OB}$, et al. Comparison of effectiveness and sensitivity using two in-office bleaching protocols for a $6 \%$ hydrogen peroxide gel in a randomized clinical trial. Oper Dent. 2017 May 1;42(3):244-52.

38. Mushashe AM, Coelho BS, Garcia PP, Rechia BC do $\mathrm{N}$, da Cunha LF, Correr GM, et al. Effect of different bleaching protocols on whitening efficiency and enamel superficial microhardness. J Clin Exp Dent. 2018 Aug 1; 10(8):e772-5

39. Bilichodmath S, Gundapaneni V, Cecil A, Bilichodmath $\mathrm{R}$. Teeth bleaching using diode laser as an adjunct to a bleaching agent. J Dent Lasers. 2018;12(2):70.

40. Barcessat AR, Gurgel-Juarez NC, Wetter NU. Vital tooth bleaching using different techniques: A clinical evaluation. Futur Dent J. 2018;5(2):1-6.

41. Hazar A, Sağlam Bc. Spectrophotometric and Morphologic Comparison of Bleaching with LED and Diode Laser. Turkiye Klin J Dent Sci. 2019;25(2):133-9.

42. Saeedi R, Ranjbar Omrani L, Abbasi M, Chiniforush N, Kargar M. Effect of Three Wavelengths of Diode Laser on the Efficacy of Bleaching of Stained Teeth. Front Dent. 2020;16(6).p.458. 42

43. Markowitz K. Pretty painful: why does tooth bleaching hurt? Med Hypotheses. 2010;74(5):835-40.

44. Kielbassa AM, Maier M, Gieren A-K, Eliav E. Tooth sensitivity during and after vital tooth bleaching: A systematic review on an unsolved problem. Quintessence Int. 2015;46(10):881-97.

45. Gopinath NM, John J, Nagappan N, Prabhu S, Kumar ES. Evaluation of dentifrice containing nano-hydroxyapatite for dentinal hypersensitivity: a randomized controlled trial. J Int oral Heal JIOH. 2015;7(8):118.

46. Jena A, Shashirekha G. Comparison of efficacy of three different desensitizing agents for in-office relief of dentin hypersensitivity: A 4 weeks clinical study. J Conserv Dent JCD. 2015;18(5):389.

47. Lee SY, Kwon HK, Kim BI. Effect of dentinal tubule occlusion by dentifrice containing nano-carbonate apatite. J Oral Rehabil. 2008;35(11):847-53.

48. Souza GDM de, Santos LM, Fernandes CA, Dantas EDV, Galvão MR, Assunção IV de. Sensitivity in dental bleaching and the use of anti-inflammatory agents. JSM Dent. 2014;2(1): 1023.

49. Borges BCD, Pinheiro MHM, De Sousa Feitosa DA, Correia TC, Braz R, Montes MAJR, et al. Preliminary 
study of a novel in-office bleaching therapy modified with a casein phosphopeptide-amorphous calcium phosphate. Microsc Res Tech. 2012;75(11):1571-5.

50. De Almeida LCAG, Costa CAS, Riehl H, dos Santos PH, Sundfeld RH, Briso ALF. Occurrence of sensitivity during at-home and in-office tooth bleaching therapies with or without use of light sources. Acta Odontol Latinoam. 2012;25(1):3-8.

51. De Paula EA, Nava JA, Rosso C, Benazzi CM, Fernandes KT, Kossatz S, et al. In-office bleaching with a twoand seven-day intervals between clinical sessions: A randomized clinical trial on tooth sensitivity. J Dent. 2015;43(4):424-9.

52. Cartagena AF, Parreiras SO, Loguercio AD, Reis A, Campanha NH. In-office bleaching effects on the pulp flow and tooth sensitivity-case series. Braz Oral Res. 2015;29(1):1-6.

53. Lo Giudice R, Pantaleo G, Lizio A, Romeo U, Castiello G, Spagnuolo G, et al. Clinical and Spectrophotometric Evaluation of LED and Laser Activated Teeth Bleaching. Open Dent J. 2016;10(1):242-50.

54. Moosavi H, Arjmand N, Ahrari F, Zakeri M, Maleknejad F. Effect of low-level Laser therapy on tooth sensitivity induced by in-office bleaching. Lasers Med Sci. 2016;31(4):713-9.

55. Bilichodmath R, Kumar Rv, Bilichodmath S, Sameera U. Diode laser in the treatment of dentinal hypersensitivity: A reliable approach. J Dent Lasers. 2018;12(2):56.

56. Abouelfotouh IFI, Fahmy OMI, Khairy AE, Salah Eldine DM. A comparative study of different bleaching techniques, regarding the color change, stability and postoperative hypersensitivity: a randomized controlled clinical trial. Stomatol Dis Sci. 2018 9;2(5):5.

57. Das S, Pudakalkatti PS, Ancia Vaz A, Kour P, Padmanabhan S. Determination of the Antibacterial Activity of Atorvastatin against Periodontal Pathogens:An in vitro study. J Interdiscip Dent. 2020;10(1):3-8.

58. Al-Maliky MA. Clinical investigation of $940 \mathrm{~nm}$ diode laser power bleaching: An in vivo study. J Lasers Med Sci. 2019;10(1):33-6.

59. Féliz-Matos L, Miguel Hernández L, Abreu N. Dental Bleaching Techniques; Hydrogen-carbamide Peroxides and Light Sources for Activation, an Update. Mini Review Article. Open Dent J. 2014; 8: 264-268.
60. Alexander L, Kommi PB, Arani N. Evaluación de la cinética de fricción entre regular y color titanio molibdeno aleación arcos. Indian J Dent Res. 2017;29(2):212-6.

61. Epple M, Meyer F, Enax J. A Critical Review of Modern Concepts for Teeth Whitening. Dent J (Basel). 2019;7(3):79.

62. Carey CM. Tooth whitening: What we now know. J Evid Based Dent Pract. 2014;14(SUPPL.):70-6.

63. Samuel W. Ad-a Report. 1988.

64. Greenwall-Cohen J, Greenwall L, Haywood V, Harley K. Tooth whitening for the under-18-year-old patient. Br Dent J. 2018 Jul 13;225(1):19-26.

65. Algarni AA, Ungar PS, Lippert F, Martínez-Mier EA, Eckert GJ, González-Cabezas C, et al. Trend-analysis of dental hard-tissue conditions as function of tooth age. J Dent. 2018 Jul 1;74:107-12.

66. Ayash G, Osman E, Segaan L, Rayyan M. Visual Versus Instrumental Shade Selection Techniques. Egypt Dent J. 2015;61(April):2011:2016.

67. Tsiliagkou A, Diamantopoulou S, Papazoglou E, Kakaboura A. Evaluation of reliability and validity of three dental colormatching devices. Int J Esthet Dent. 2016;11(1):110-24.

68. Dozić A, Kleverlaan CJ, El-Zohairy A, Feilzer AJ, Khashayar G. Performance of five commercially available tooth color-measuring devices. J Prosthodont. 2007 Mar;16(2):93-100.

69. Marson FC, Sensi LG, Vieira LCC, Araújo É. Clinical evaluation of in-office dental bleaching treatments with and without the use of light-activation sources. Oper Dent. 2008 Jan;33(1):15-22.

70. Joiner A. Tooth colour: A review of the literature. J Dent. 2004;32(SUPPL.):3-12.

71. Gómez-Polo C, Gómez-Polo M, Celemin-Viñuela A, Martínez Vázquez De Parga JA. Differences between the human eye and the spectrophotometer in the shade matching of tooth colour. J Dent. 2014 Jun 16;42(6):742-5.

72. Palé M, Mayoral JR, Llopis J, Vallès M, Basilio J, Roig M. Evaluation of the effectiveness of an in-office bleaching system and the effect of potassium nitrate as a desensitizing agent. Odontology. 2014;102(2):203-10.

73. Mariam R, Mathews M, Sudeep S, Dinesh N. Clinical evaluation of laser bleaching vs. conventional in-office bleaching. J Dent Lasers. 2013;7(2):54. 
74. Calderini A, Sciara S, Semeria C, Pantaleo G, Polizzi E. Comparative clinical and psychosocial benefits of tooth bleaching: different light activation of a $38 \%$ peroxide gel in a preliminary case-control study. Clin Case Reports. 2016;4(8):728-35.

75. Fekrazad R, Alimazandarani S, Kalhori KA, Assadian H, Mirmo-Hammadi 51 Dds S-M. Laser and power bleaching tooth color Comparison of laser and power bleaching techniques in tooth color change. J Clin Exp Dent. 2017;9(4):511-6.

76. Hayward R, Osman Y, Grobler SR. A Clinical Study of the Effectiveness of a Light Emitting Diode System on Tooth Bleaching. Open Dent J. 2012 Oct 2;6(1):143-7.

77. Minoux M, Serfaty R. Vital tooth bleaching: biologic adverse effects-a review. Quintessence Int. 2008;39(8):645-59.

78. Bacaksiz A, Tulunoglu O,Tulunoglu I. Efficacy and stability of two in-office bleaching agents in adolescents: 12 months follow-up. J Clin Pediatr Dent. 2016;40(4):269-73.

79. Bernardon JK, Sartori N, Ballarin A, Perdigão J, Lopes G, Baratieri LN. Clinical performance of vital bleaching techniques. Oper Dent. 2010;35(1):3-10.

80. Kossatz S, Dalanhol AP, Cunha T, Loguercio A, Reis A, Kossatz S, et al. Effect of Light Activation on Tooth Sensitivity After In-Office Bleaching. Oper Dent. 2011; 251-7.
81. Orchardson R, Gangarosa LP, Holland GR, Pashley DH, Trowbridge HO, Ashley FP. Dentine hypersensitivity-Into the 21st century. Arch Oral Biol. 1994;39(Suppl):113S-119S

82. Sabry Tawfik S, Khairy MAE, ElBaz MAE, El korashy MEM. Evaluation of post-bleaching hypersensitivity using desensitizing agent before and /or after in-office bleaching: A randomized clinical trial. F1000Research. 2019;8:1762.

83. Brännström $\mathrm{M}$, Aström $\mathrm{A}$. The Hydrodynamics Of The Dentine; Its Possible Relationship To Dentinal-Pain. Int Dent J.1972 ;22(2):219-27.

84. Davari AR, Ataei E, H Assarzadeh H. Dentin Hypersensitivity: Etiology, Diagnosis and Treatment; A Literature Review. J Dent. (Shiraz) 2013; 14(3):136-145.

85. Kaufman G. Basic pharmacology of non-opioid analgesics. Nurs Stand. 2010;24(30):55-66.

86. Dawson Sharif AB, Smith PA, Brunton PM. A Clinical Study Comparing the Efficacy and Sensitivity of Home vs Combined Whitening. Clin Res. Oper Dent. 2011; 36(5):460-6.

87. Alqahtani MQ. Tooth-bleaching procedures and their controversial effects: A literature review. Saudi Dent J. 2014; 26(2):33-46

88. Charakorn P, Cabanilla LL, Wagner WC, Foong WC, Shaheen J, Pregitzer R, et al. The effect of preoperative ibuprofen on tooth sensitivity caused by in-office bleaching. Oper Dent. 2009 Mar; 34(2): 131-5. 